\title{
NUEVOS DATOS PARA EL PERIODO DE CERÁMICA INICIAL EN EL VALLE DE CASMA
}

\author{
Rosa Fung Pineda
}

En Marzo de 1968 cuando visité Tortugas, un balneario ubicado más o menos a $20 \mathrm{~km}$ al norte de la ciudad de Casma, recogí algunos materiales arqueológicos de un yacimiento sobre la terraza marina que se levanta en el sector norte de la Bahía. Este yacimiento con restos de estructuras de piedras angulares canteadas, se estaba destruyendo para construir una casa.

De regreso a Lima, cuando estuvimos examinando los tiestos, una vez limpios, descubrimos una sorprendente semejanza entre los decorados de Tortugas (Lam. II c, e; Fig. 1 a, c); al par que, acompañados por el Dr. Donald E. Thompson, recogimos en 1965 (lam. II a-b; fig. $1 \mathrm{~b}, \mathrm{~g}$ ) en una de las estructuras que él identificó como C1 dentro de los sitios que conjuntamente con el Dr. Donald Collier estudió durante 1956 (lam. I) y los de la primera fase de cerámica inicial de Las Aldas.

La colección de cerámica de Tortugas constituye una sola unidad estilística. Consta de 8 fragmentos decorados, 33 bordes de ollas, 1 base aplanada de vasija y más de 150 piezas que pertenecen a cuerpos de ollas (lam. II c-i; figs. $1 \mathrm{a}, \mathrm{c}, \mathrm{d}, \mathrm{f} ; 2-4)$.

Tanto los ejemplares decorados como los sencillos comparten las mismas características generales referentes al desgrasante, cualidad de la pasta y tratamiento de las superficies.
El desgrasante abundante y tosco, de granos blancos y negros, incluye, ocasionalmente, piedrecillas de tamaños hasta de $3 \mathrm{~mm}$. Predominan los granos blancos, de cuarzo. Como hemos recuperado algunos trozos de cuarzo y siendo los granos angulares y subangulares en su mayoría derivados de este mineral, deducimos que trituraron el cuarzo para utilizarlo mezclado con la pasta. En uno que otro tiesto afloran partículas de pirita, seguramente ellas vinieron integradas a la arcilla.

La pasta es de color ciena claro a ciena oscuro, de contextura porosa, algunas veces laminar, pero no se desmenuza fácilmente. Muy pocos ejemplares de los sencillos muestran manchas oscuras.

La superficie interior, alisada con implemento duro típicamente es irregular y un poco áspera al tacto. Un buen número de fragmentos, por otro lado, denota alisamiento con los dedos o algo similar, flexible, que ha dejado huellas filiformes, mientras que unos cuantos ofrecen un aspecto de haber sido raspados. El acabado de la superficie exterior se hizo empleando un objeto firme que en casi todos los casos dejó visibles, líneas anchas y brillosas. Aquel tratamiento ha sido denominado pebble polished y fue reconocido por primera vez, en la cerámica inicial de Ancón (Willey y Corbett, 
1954:54). El color típico es el marrón rojizo. En ciertas ocasiones esta superficie aparece manchada por defectos de la cocción y con concentraciones de burbujitas. Usualmente el exterior de los tiestos sencillos aparece tiznado de hollín y el interior adherido de sustancias quemadas, lo que prueba que la mayoría de los fragmentos derivan de vasijas de cocina. Sin embargo un borde de olla y cuatro de los fragmentos de cuerpos decorados (lam. II c-f; fig. $1 \mathrm{a}, \mathrm{c}-\mathrm{d}, \mathrm{f}$ ) estaban ennegrecidos por el fuego hecho que nos está demostrando que los recipientes que emplearon para cocer los alimentos también fueron ornamentados.

El grosor de los tiestos sencillos varía entre 3 a $101 / 2 \mathrm{~mm}$. Lo más frecuente es $5 \mathrm{~mm}$, pero no es raro encontrar en un mismo fragmento espesores diferentes, por ejemplo $31 \frac{1}{2}$ y $4 \frac{1}{2} ; 5$ $1 / 2$ y $7 \mathrm{~mm} ; 3$ y $61 / 2 \mathrm{~mm} ; 5$ y $9 \mathrm{~mm}$.

La dureza en la escala de Mohs corresponde entre 4 a 9, siendo 9 el más preponderante. Eso indica que es una cerámica muy consistente.

Las ollas sencillas tuvieron base aplanada, a juzgar por las evidencias y labios redondeados (fig. $2 \mathrm{a}-\mathrm{c}$ ); plano-redondeados (fig. $2 \mathrm{f}-\mathrm{g}$ ); planos (fig. $2 \mathrm{~h}-\mathrm{m}$ ); perfilados (fig. $3 \mathrm{a}-\mathrm{d}$ ) o con un leve y corto bisel exterior (fig. 3 c-g). Destacan, pero no por su número puesto que son relativamente escasos en nuestra muestra, los bordes de labios ligeramente volteados hacia afuera (fig. $3 \mathrm{~h}-\mathrm{j}$ ). Semejante clase de bordes hemos identificado en la cerámica de los niveles inferiores de Ancón excavada por el Dr. Ramiro Matos Mendieta y que se halla depositada en el Museo de Universidad Mayor San Marcos. También aparece en el complejo Guañape del valle de Virú (Strong, Evans y Lilien, 1952): gracias a la gentileza de los Dres. Betty J. Meggers y Clifford Evans del Smithsonian Institution pudimos examinar en 1968 la muestra que se encuentra allí y ofrecer ahora algunas ilustraciones para su comparación (fig. 5) haciendo la salvedad de que como el material fue excavado por niveles arbitrarios y luego clasificado, en tipos porcentuales, método que hemos criticado (Fung, Ms.:6), los bordes pueden pertenecer a más de una fase, como creemos que es el caso del borde 15 de la lámina 5 que en Las Aldas recién se hace presente en la tercera fase de la cerámica inicial (Fung, Ms.:
99; Fig. 23 d-3). Empero, reconocemos que lo que ocurrió en Las Aldas, no necesariamente tuvo que ocurrir en Virú. De todos modos, anteriormente habíamos postulado que el conjunto de cerámica de los períodos Guañape Temprano y Guañape medio aislado y descrito por Strong, Evans y Lilien (1952) pertenece al período de cerámica inicial anterior a la aparición del complejo Chavín en la zona (Fung, Ms.: 206-216).

Los bordes de Virú que ilustramos pertenecen a dos tipos: Guañape Negro Sencillo y Guañape Rojo Sencillo. A nuestro parecer, ambos pueden ser considerados como uno solo. La cerámica sencilla de Guañape se diferencia de la de Tortugas por el desgrasante que es de granos negros y blancos sin un predominio notable de los últimos, incluido en una pasta muy suave y friable y por las huellas del pulidor apenas visible sobre la superficie exterior. En cuanto a los tipos de decorados características del Complejo Guañape: Listón presionado con los Dedos y Listón inciso (Lam. III) se destacan por su ausencia en la actual colección de Tortugas, en cambio, el tipo punteado de Virú (Strong, Evans, Lilien, 1952: 283-84) evoca conexiones estilísticas con el representativo de Tortugas.

La otra colección en donde existen los discutidos bordes volteados hacia afuera pertenece a la cerámica inicial de Huaca Prieta, Chicama, excavada por el Dr. Junius Bird, (1948:26) quién generosamente puso a mi disposición, para su revisión, la muestra que posee el "American Museum ofNatural History" de Nueva York y, además, me ha brindado sus apuntes. Incluimos en esta publicación algunas ilustraciones (fig. 6A) que permitirán a los lectores la oportunidad de hacer sus propias distinciones.

De acuerdo a los puntos y la discusión personal sostenida con el Dr. Junius Bird, se desprende que el complejo de cerámica "proCupisnique" que incluye, principalmente, ollas de borde delgados, directos o volteados suavemente hacia afuera, fue aislado en el sondeo 4 de Huaca Prieta. Con el mencionado complejo vinieron asociados dos sellos, uno en forma de rodillo y otro plano, bien cubiertos de pintura roja; espejos de azabache, tabletas y tubos 
de rapé, de hueso y dos figurines de arcillas, modeladas sólidamente y en posición sentadas con trazos post-cocción de pigmento rojo. La pasta de color rojizo, pobremente cocida, incluye temperamento fino de granos blancos.

De tortugas poseemos un fragmento modelado sólido, posiblemente de figurina, con residuos de post-cocción de pigmento rojo en las incisiones (Lam. II h).

Se conocen figurinas para el periodo de Cerámica Inicial en Ancón (Strong, 1925: fig. 6) y en Las Aldas (Ishida et al, 1960: 103). Distinguidos americanistas, Strong, entre los primeros, Lathrap y otros (Strong, 1925: 154; Lanning, 1962: 594; Lathrap, 1966: 126) han señalado sus vinculaciones históricas con las de Mesoamérica. Nosotros hemos argumentado en contra tal conexión. (Fung, Ms.: 14-18).

La figurina de Tortugas, en todo caso, estaría relacionada con las de Las Aldas y los otros elementos.

Prosiguiendo con la descripción de la cerámica de Tortugas, le toca a los decorados restantes. Un espécimen incluido dentro de dicha categoría, en realidad consiste de un pedazo de tierra cocida con una impronta de tejido llano (lam. II g).

La decoración de la unidad de Tortugas se basa en puntuaciones profundas más o menos circulares o alargadas acompañadas, en un ejemplo, de una línea incisa, ancha, irregular (lam. II f; fig. 1f). Las puntuaciones petaloidales han sido efectuadas empujando un punzón grueso y romo en ángulo agudo, resultando así mucho más honda el área de la presión final (Lám. II c, e; Fig. 1 a, c).

Excepto por el borde de una olla decorada, no sabemos qué otras formas produjeron. Solamente podemos indicar que los demás tiestos derivaron de vasijas de cocina porque fueron hallados ennegrecidos de hollín. Tres exhiben un ángulo (fig.1 c, d, t) igual que los del C1 (fig. $1 \mathrm{~b}, \mathrm{~g}$ ).

La reducida muestra de $\mathrm{C} 1$, Casma, comprende, fuera de los 2 tiestos decorados, dos fragmentos sencillos de cuerpo y un borde del- gado de olla (fig. 1 e). Como yacieron sobre la superficie del sitio, expuesto al sol y al aire, están erosionados. Se distingue que la pasta laminar, aunque no se desmorona, tiene abundante desgrasante de granos toscos negros y blancos, predominando los últimos. La superficie interior irregular fue suavizada con los dedos, apreciándose las hendiduras que dejaron.

La fase 1 de la Cerámica Inicial de Las Aldas está representada por un conjunto relativamente pequeño (Fung, Ms. 69-74). Contamos con un total de 10 bordes de ollas (fig. 6B) dos de ellos delgados, ligeramente tornados hacia fuera, pero cuyos labios sensiblemente se encuentran muy erosionados, de allí que nos hemos sentido impedidos de ilustrarlos. Tortugas, por otra instancia, carece de golletes de botella, pero puede ser que ampliando la colección, se reconozca a este tipo de recipiente. Las diferencias de la fase 1 de Las Aldas comprometen las huellas del pulidor sobre las superficies exteriores que no son ni tan marcadas ni tan frecuentes como en Tortugas y se desconocen hasta el momento las ollas decoradas. Ellas aparecerán mas tarde.

Fuera de la cerámica, un punto importante de relación entre periodo de Cerámica Inicial de La Aldas y el de Tortugas representa la ocurrencia en ambos sitios de los trozos de cuarzo y los escupitajos de corteza.

Antes de continuar quisiéramos indicar que entre los residuos alimenticios del sitio de Tortugas, reconocimos algunas pepas de lúcumas, restos de guayaba (?), calabaza, vértebras de pescado, abundantes conchas y algunos huesos de mamíferos no identificados.

La importancia de la sorprendente similitud estilístico -decoración característica de pasta, desgrasante, y acabado de las superficies interiores- entre la cerámica de $\mathrm{C} 1$, Tortuga y la Aldas, radica en que nos permite desarrollar ciertas hipótesis concernientes a la historia de una serie de complejos arquitectónicos en el valle de Casma que hasta hoy permanecen sin fecharse.

En 1962, el Dr. Donald Collier dio a conocer una secuencia para el valle de Casma en base de la clasificación de las colecciones de 
cerámica que fueron recuperadas a través de las colecciones de cerámica que fueron recuperadas a través de las exploraciones y excavaciones que realizara cuatro años atrás (Collier, 1969). Luego, el Dr. Donald E. Thompson, quien fue asistente del Dr. Collier, ordenó los patrones de asentamiento de acuerdo a esa cronología (Thompson,: 1962, 1964 a; 1964 b). Thompson nos indica la dificultad de seriar un cierto número de pirámides escalonadas, de caras paramentadas, en el área comprendida entre el sur de de Costa Norte y el extremo Norte de la Costa Central que abarca el valle de Casma, debido a los siguientes factores: la ausencia o muy poca cantidad de tiestos superficiales asociados a las estructuras; otras veces, la mezcla de cerámica tanto tardía como temprana y, por último, la recuperación de los sitios utilizándolos como comentarios que, más tarde al ser excavados sin ningún interés científico, ha dado lugar a la dispersión de la fragmentería tardía en construcciones que arquitectónicamente se las considera como tipos tempranos (Thompson, 1962).

Debemos manifestar que las mencionadas interpretaciones temporales ocurrían en una época cuando recién se comenzaba a definir la Cerámica Inicial en el Perú y cuando aún prevalecía la opinión de que los edificios públicos de carácter ceremonial fueron construidos recién durante el período del Complejo Chavín u Horizonte Temprano.

C1 es identificado como una de las diez pirámides enigmáticas descritas por Thompson que se caracterizan por la notable escasez de tiestos. Se trata de una estructura de piedras angulares engastadas en barro, del sub tipo corridore. El plano de la pirámide es rectangular y se levanta unos 8 a $16 \mathrm{~m}$ del suelo. En el centro, a lo largo de la cima, hay una hendidura que corresponde a los patios inferiores, que a su vez, están flanqueados por cuartos y plataformas. C1, además, contiene algunas edificaciones de adobes cónicos igual que el monumental Sechín Alto (Thompson, 1962: 265).

Todas las diez pirámides han sido asignadas al período denominado Formativo. El sub- tipo corridore perteneciente, según Thompson al Formativo Tardío.
El Formativo Tardío en la cronología de Collier está representado por la cerámica del estiló Patazca que es un Chavín derivado o sea, un estilo que carece de los elementos específicos Chavín (Collier, 1962: 413).

En la gran pirámide de Sechín Alto, Collier encontró asociado a la estructura de adobes cónicos, superpuesta a la de piedra, un 100\% de cerámica del estilo Patazca (Collier, comunicación personal, 1966). Por otro lado, en sus excavaciones dentro del perímetro del mismo sitio, obtuvo, al parecer, una estratigrafía invertida. Gualaño al que le asignó una fecha de 750 a.C. fue ubicado después del estilo Cahuachuco con unos 1,200 a.C. (Collier, 1962: 412). Las dataciones de $\mathrm{C} 14$ posteriormente han contradicho este orden estratigráfico, estableciendo un fechado de 690 a.C. para el estrato Cahuachuco y de 1,450 a.C. para el de Gualaño (Berger, et al. 1965: 347). Aplicando el nuevo método de la Termoluminescencia a tiestos de la misma colección estratigráfica ha producido igual resultado, en el sentido de que la cerámica de Cahuachuco es más joven que la Gualaño (Mazess y Zimmerman, 1966: 347-348).

Cuando el Dr. Collier describió los estilos de cerámica casmeña, señalo la similitud del estilo Gualaño con la última parte de Guañape Temprano (Collier, 1962: 413).

La cerámica sencilla del estilo Gualaño es delgada $(3-8 \mathrm{~mm})$, de color que va del negro al rojo. La pasta es deleznable, exhibiendo un pobre control del fuego. La superficie interior está alisada toscamente o raspada y el exterior exhibe las marcas del pulimento realizado con un instrumento duro. Las formas reconocidas son ollas globulares pequeñas o medianas, de abertura constreñida y bordes ligeramente engrosados con labio redondeado o angular. Se encuentran vasijas de forma similar pero con los bordes levemente volteados hacia afuera. La decoración que es extremadamente rara gira alrededor de líneas incisas, áreas de puntuaciones más o menos circulares y un filete o apéndice inciso. Junto con Gualaño Sencillo aparece una pequeña cantidad de alfarería negra bruñida y fragmentos de alfarería roja que proceden de pequeñas vasijas globulares de boca estrecha, tazas globulares y tazas de bases planas (Collier, 1962: 413). 
Collier no ha ilustrado la cerámica del estilo Gualaño, pero teniendo en cuenta la cronología absoluta, la comparación y la descripción que nos ofrece, podemos proponer que estamos frente a un complejo de cerámica inicial evidentemente relacionado con el Guañape, Huaca Prieta, Tortugas, C1, Las Aldas y Ancón.

Si la unidad cerámica del sitio de Tortugas indica vinculaciones innegables con la fase 1 de la cerámica inicial de Las Aldas y si los dos fragmentos decorados de $\mathrm{C} 1$ se presentan como homólogos a los del mismo tipo de Tortugas, resulta válido postular que la edificación data, al menos, de ese periodo, y, si C1 posee adobes cónicos superpuestos igual que Sechín Alto y si los adobes cónicos se los diagnostica como elementos del complejo Chavín, tenemos en C1 una ocupación tardía por algunas de las gentes Chavín, situación idéntica a la de Las Aldas pero sin la asociación de adobes cónicos sino más bien de un gran pozo ceremonial circular (Fung, Ms.), estructura que también ha sido descubierta en Sechín Alto y otros sitios (Fung y Williams, Ms; Fung, Amano y Miyazaki, Ms).

En otra ocasión, hemos postulado las relaciones entre Guañape Medio y las fases 2 y 3 de la Cerámica Inicial de Las Aldas, subrayando que recién, por primera vez, durante este período se identifica una estructura de tipo ceremonial en Virú, el Templo de Las Llamas (Strong y Evans, 1952: 27-39; Fung, Ms. 206-216). Estas relaciones apoyarían la impresión original de Collier de la semejanza estilística entre la cerámica de la última parte de Guañape Temprano y la del estilo Gualaño que el encontró en Sechín Alto. Aquí debemos anotar que con el estrato Gualaño, las excavaciones no alcanzaron terreno culturalmente estéril, por lo tanto, Sechín Alto debió haberse empezado a construir antes, lo mismo que hemos propuesto para Las Aldas, asumiendo que fue un centro ceremonial dependiente de Sechín Alto (Fung, Ms.; Fung 1969: 143-144).

C1 y Tortugas, en consecuencia, formarían parte de este gran complejo de Sechín AltoLas Aldas.
La concentración en el pequeño valle de Casma de un sistema de centros ceremoniales con construcciones monumentales (Kosok, 1965: 215) que comprenden a una pirámide, la de Sechín Alto, que sobrepasa en sus dimensiones a la Huaca del Sol, producto del Estado Mochica unos 1500 años después, descubre el panorama de un proceso socio-político mucho más amplio y complejo de lo que habíamos supuesto para un periodo tan temprano en los Andes Centrales. El tratar de elucidarlo resulta fundamental para la comprensión del surgimiento de las civilizaciones en el Nuevo Mundo.

\section{RECONOCIMIENTOS}

Estamos muy agradecidos a los Señores Y.Miyazaki, Félix Caycho, Abraham Guillén y Wilfredo Loayza por la generosa colaboración con los dibujos y las fotografías, del Arq⿳⺈ Carlos Williams León quien nos proporcionó el mapa que acompaña al texto en donde ha sido posible ubicar el sitio C1 gracias a la información grafica del Dr. Collier. Igualmente agradecemos a los Dres. Junius Bird, Betty Meggers y Clifford Evans.

El material de Tortugas y C1 se encuentra depositado en el Museo de Arqueología y Etnología de la Universidad Mayor de San Marcos.

\section{BiBLIOGRAFÍA}

BERGER, R; G J. FERGUSON y W. F. LIBBY

1965 "UCLA Radiocarbon dates IV", vol. 7 p. 347. Published Annually by the American Journal of Science. Yale University Press, New Haven.

BIRD, Junius

1948 "Preceramic cultures in Chicama and Viru". En: A Reappraisal of Peruvian Archaeology. Editado por Wendel C. Bennett. Memoirs of the Society for American Archaeology, $\mathrm{N}^{\circ} 4$, pp. 21-28. Menasha.

COLLIER, Donald

1962 "Archaeological Investigation in the Casma Valley, Peru". Separata: akten des 34 Internationalen Amerikanistenkongresses, Wien 18. bis. Juli 1960. pp. 411-417. Horn-Wien. 
FUNG PINEDA, Rosa

Ms. Las Aldas. Su ubicación dentro del progreso histórico del Perú Antiguo. Tesis para obtener el Grado de Doctor en Letras, Especialidad de Antropología. Facultad de Letras. Universidad Nacional Mayor de San Marcos, Lima, 1967.

1969 "Observaciones arqueológicas sobre la obra "Perú Antiguo de los Incas". Tecnia, $\mathrm{N}^{\circ}$ 3, pp. 142-152. Publicación de la Universidad Nacional de Ingeniería de Lima.

FUNG PINEDA, Rosa; Yoshitaro AMANO; Yasushi MIYAZAKI

Ms. Excavaciones en el sitio de Bermejo. Trabajo presentado al XXXIX Congreso Internacional de Americanistas. (Lima, 2-9 Agosto de 1970).

FUNG PINEDA, Rosa y Carlos WILLIAMS LEÓN

Ms. Exploraciones y excavaciones en el valle de Casma. Trabajo presentado al XXXIX Congreso Internacional de Americanistas (Lima 2-9 de Agosto de 1970)

ISHIDA, Eiichiro et al.

1960 Andesu: Tokyo Daigaku Andesu chitai gakujutsu chesadan 1958 nendo hokokusho. Andes: the report of the University of Tokyo. Scientific expedition to the Andes in 1958. Bijitsu Shuppan-sha, Tokyo.

KOSOK, Paul

1965 Life, land and water in ancient Peru. Long Island University Press. New York.

LANNING, Edward Putnam

1962 "Comentario: Andes the report of the University of Tokyo Scientific Expedition to the Andes in 1958" por Eiichiro Ishida y Otros. Amerícan Antiquity. Vol. 27, $\mathrm{N}^{\circ}$ 4, pp. 594-595. Salt Lake City

LATHRAP, Donald W.

1966 "Nueva evidencia par los orígenes de las civilizaciones Andinas". (Traducido de Science, vol. 148, pp. 796-799, Mayo de 1965) Cuadernos de Investigaciones $\mathrm{N}^{\circ} 1$,
Antropología, pp. 117-128. Facultad de Letras y Educación. Universidad Nacional Hermilio Valdizán, Huánuco.

MAZESS, Richard B. y D. W. ZIMMERMAN

1966 "Pottery dating from Thermoluminescence". Separata: Science. Vol. 152, N 3720 , pp. 47-348. Washington D.C.

STRONG, William Duncan

1925 "The Uhle pottery collection from Ancon". University of California Publications in American Archaeology and Ethnology, Vol. 21, № 4, pp. (i-ii), 135-190 Berkely

STRONG, Williarn Duncan y Clifford EVANS Jr.

1952 "Cultural Stratigraphy in fue Viru Valley, northern Peru; The Formative and Florescent Epochs". Columbia Studies in Archaeology and Ethnology. Vol. IV. Columbia University Press, New York.

STRONG, William Duncan; Clifford EVANS y Rosen LILIEN

1962 "Description of Pottery types". Appendix 1. En: Cultural Stratigraphy in the Viru Valley, Northern Peru; The Formative and Florescent Epochs por William Duncan Strong y Clifford Evans, Jr. Columbia Studios in Archaeology and Ethnology, vol. IV. Columbia University Press, New York.

THOMPSON, Donald

1962 "The problem of dating certain stone-faced, stepped pyramids on the north coast of Peru". Southwestern Journal of Anthropology, Vol. 8, № 4, pp. 291-301 Albuquerque.

1964a "Formative period architecture in the Casma Valley, Peru". Separata: Actas y Memorias del XXXV Congreso Internacional de Americanistas, México 1962.

1964b "Postclassic innovations in architecture and settlement patters in the Casma Valley, Peru". Separata: Southwestern Journal of Anthropology, Vol. 20, № 1, pp. 91-105. Albuquerque. 


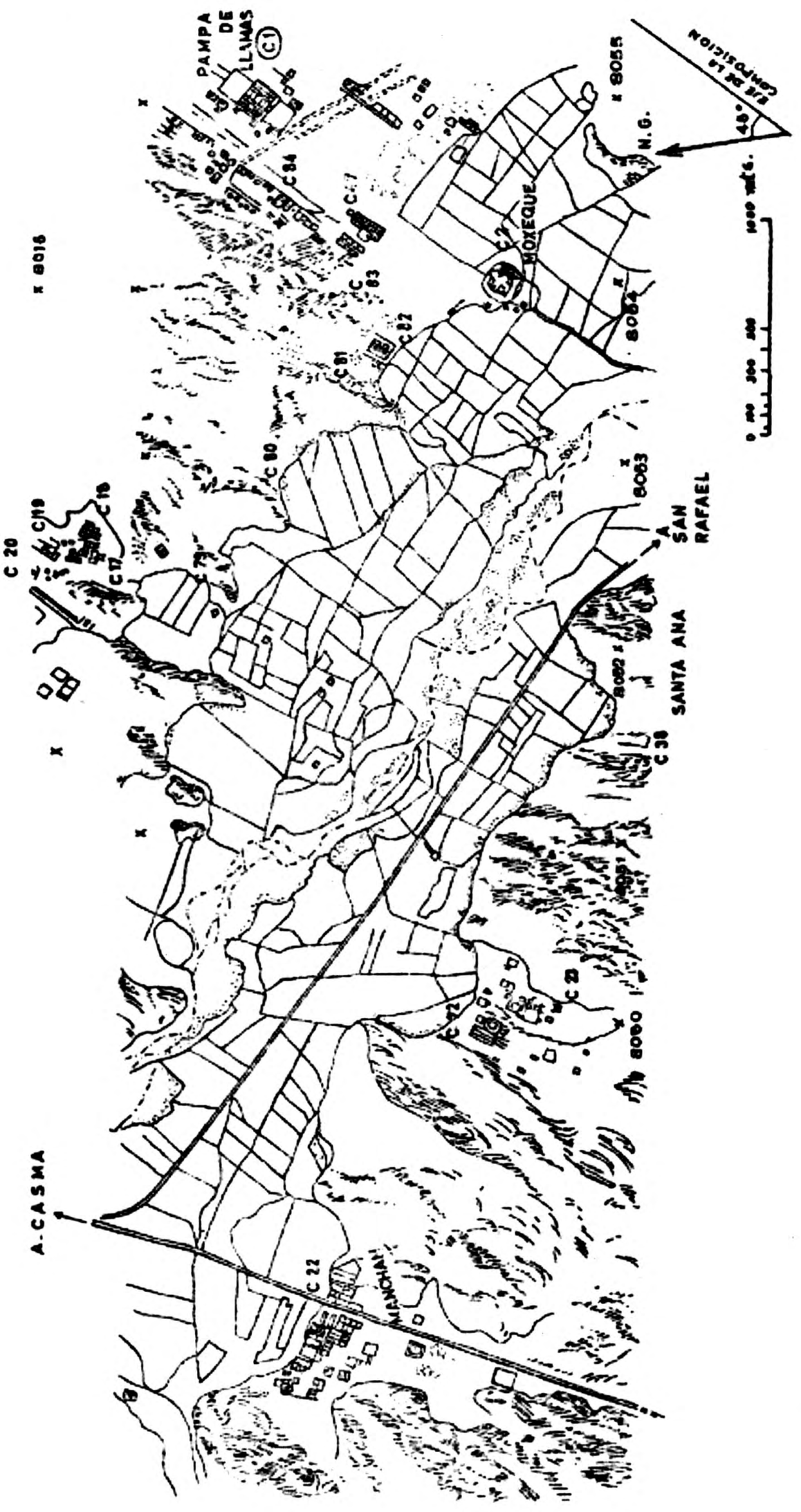



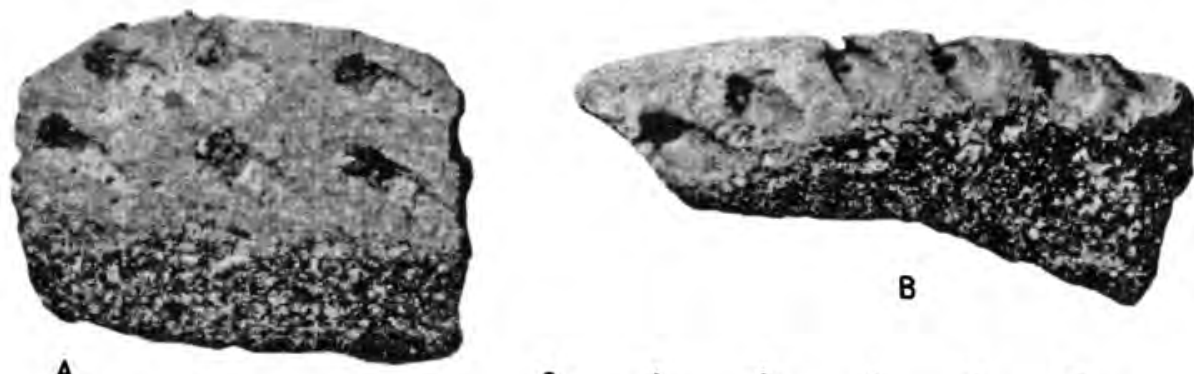

A
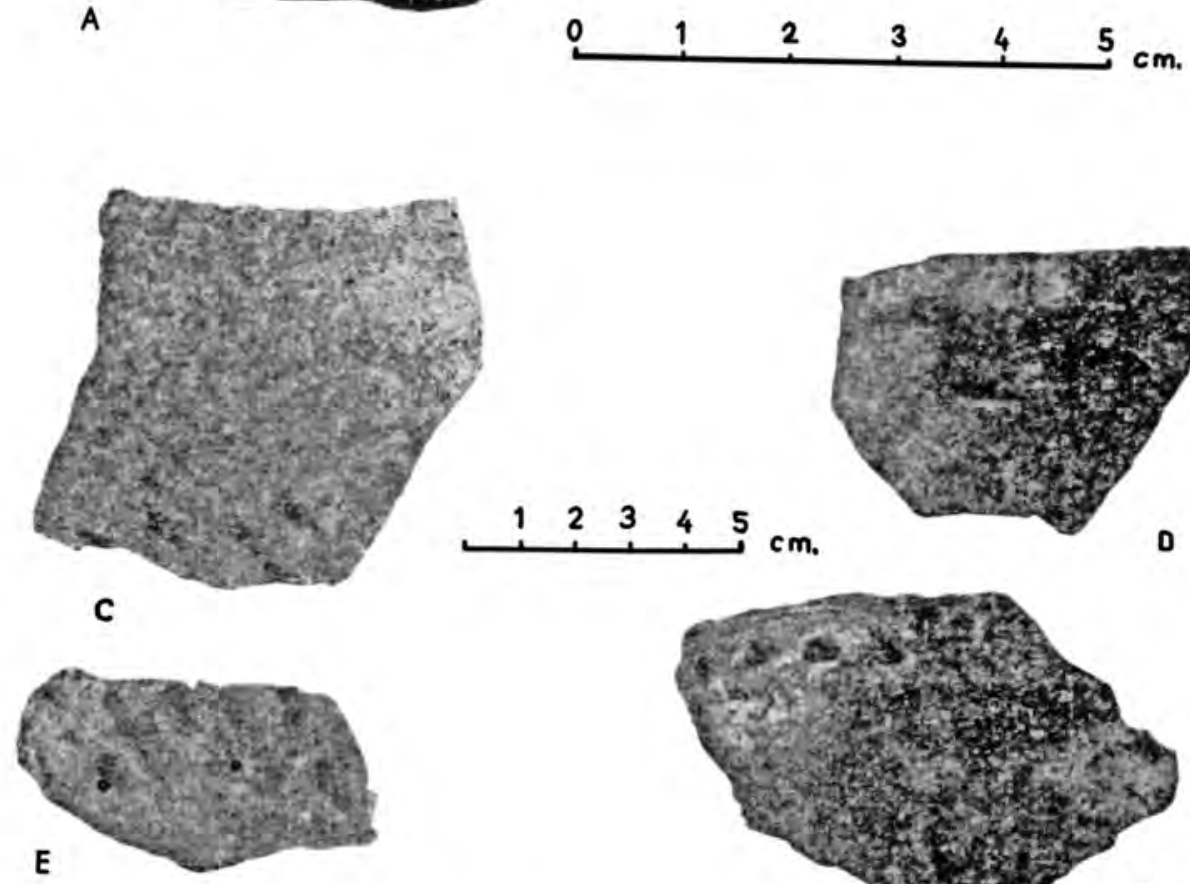

G
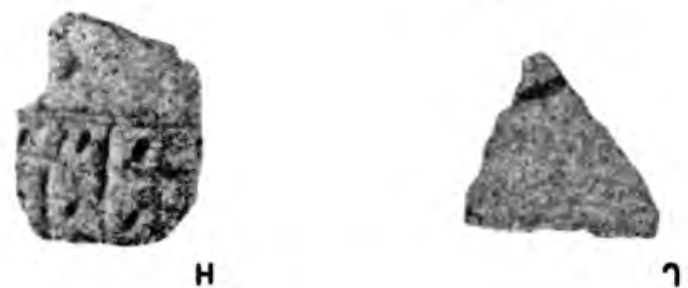


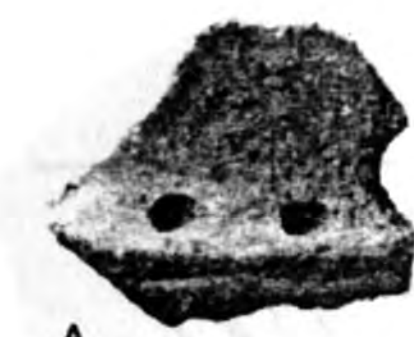

A
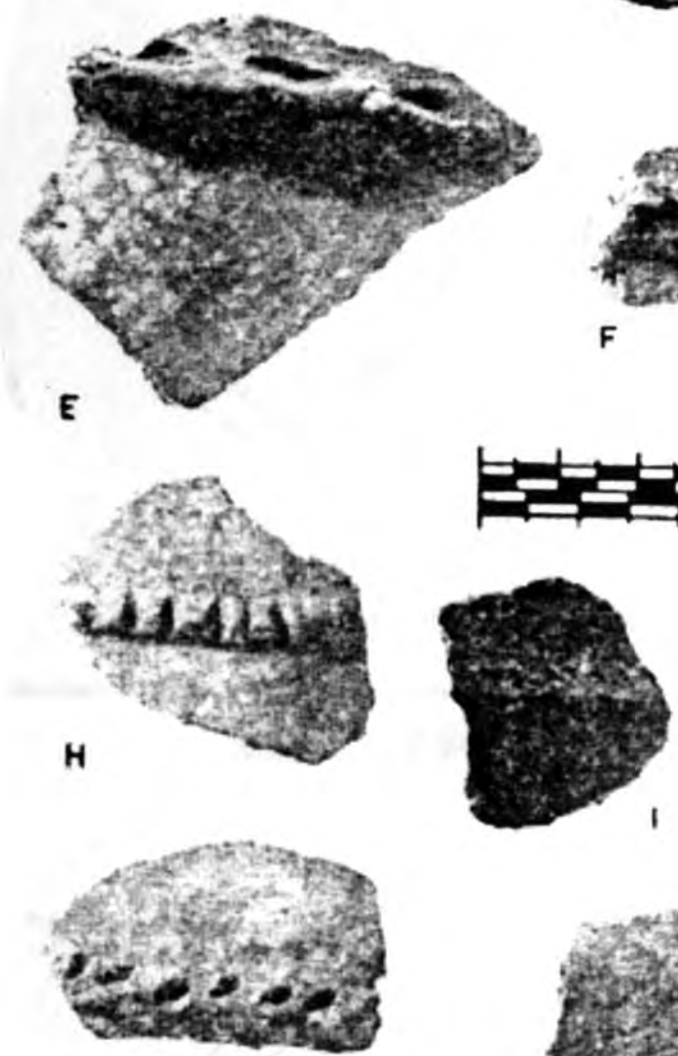

L
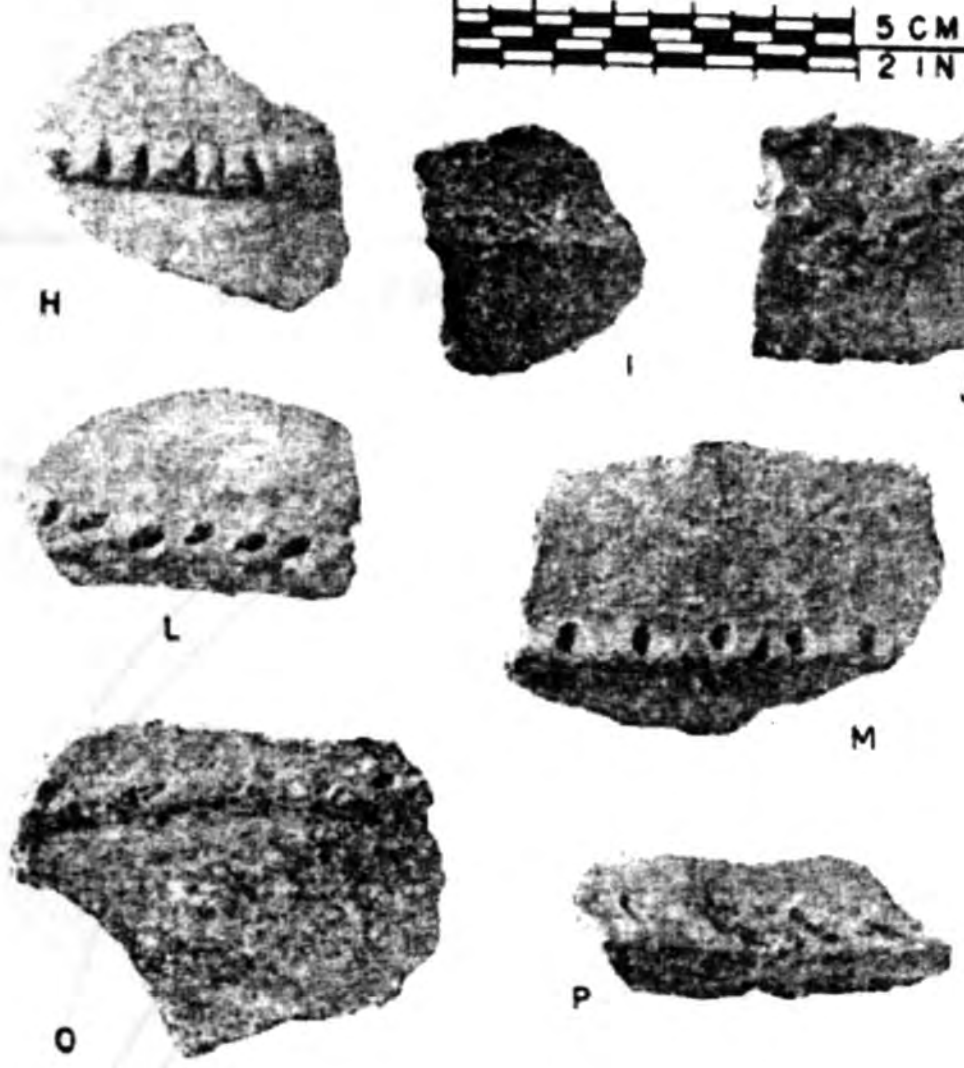
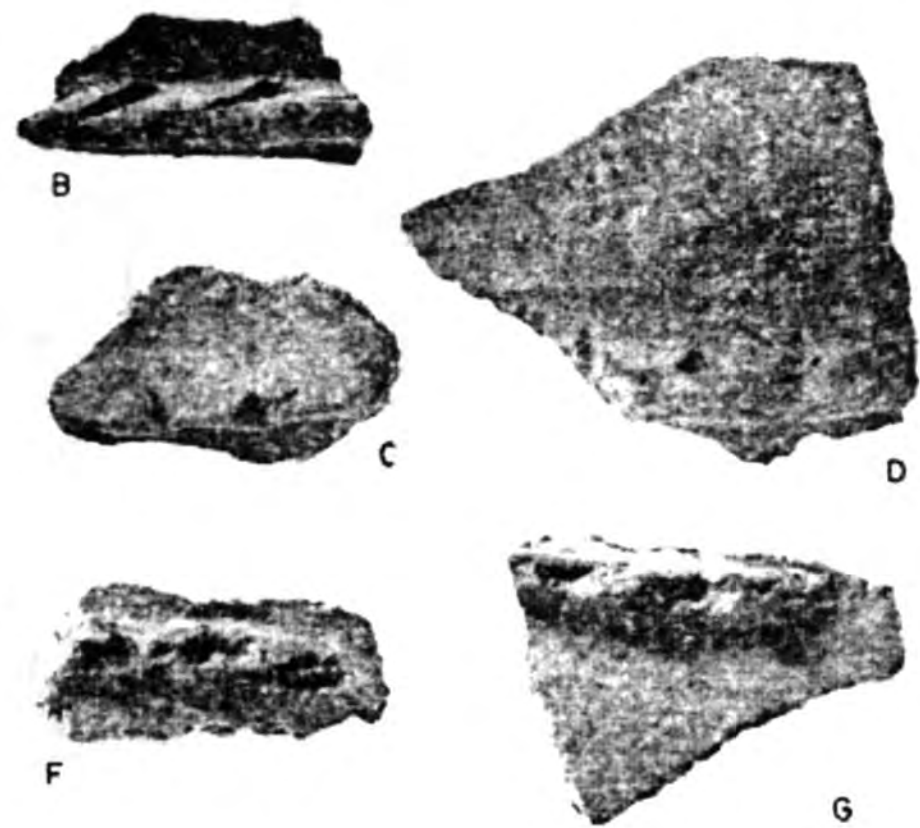

G
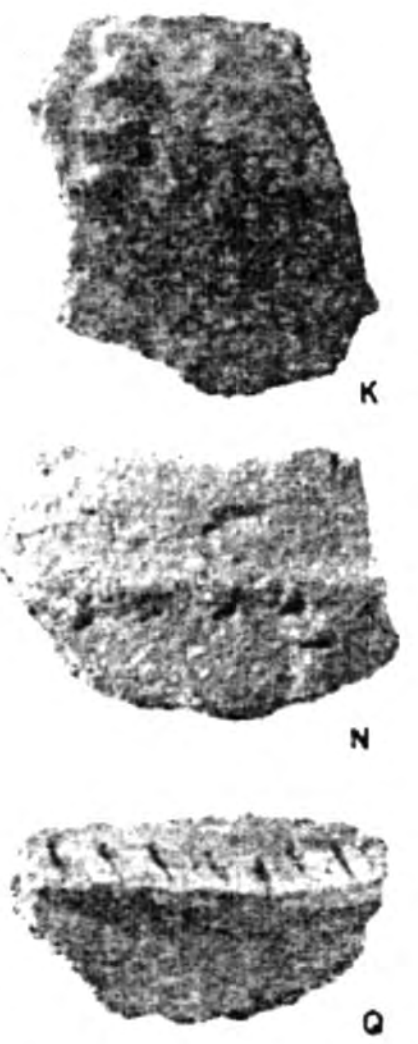

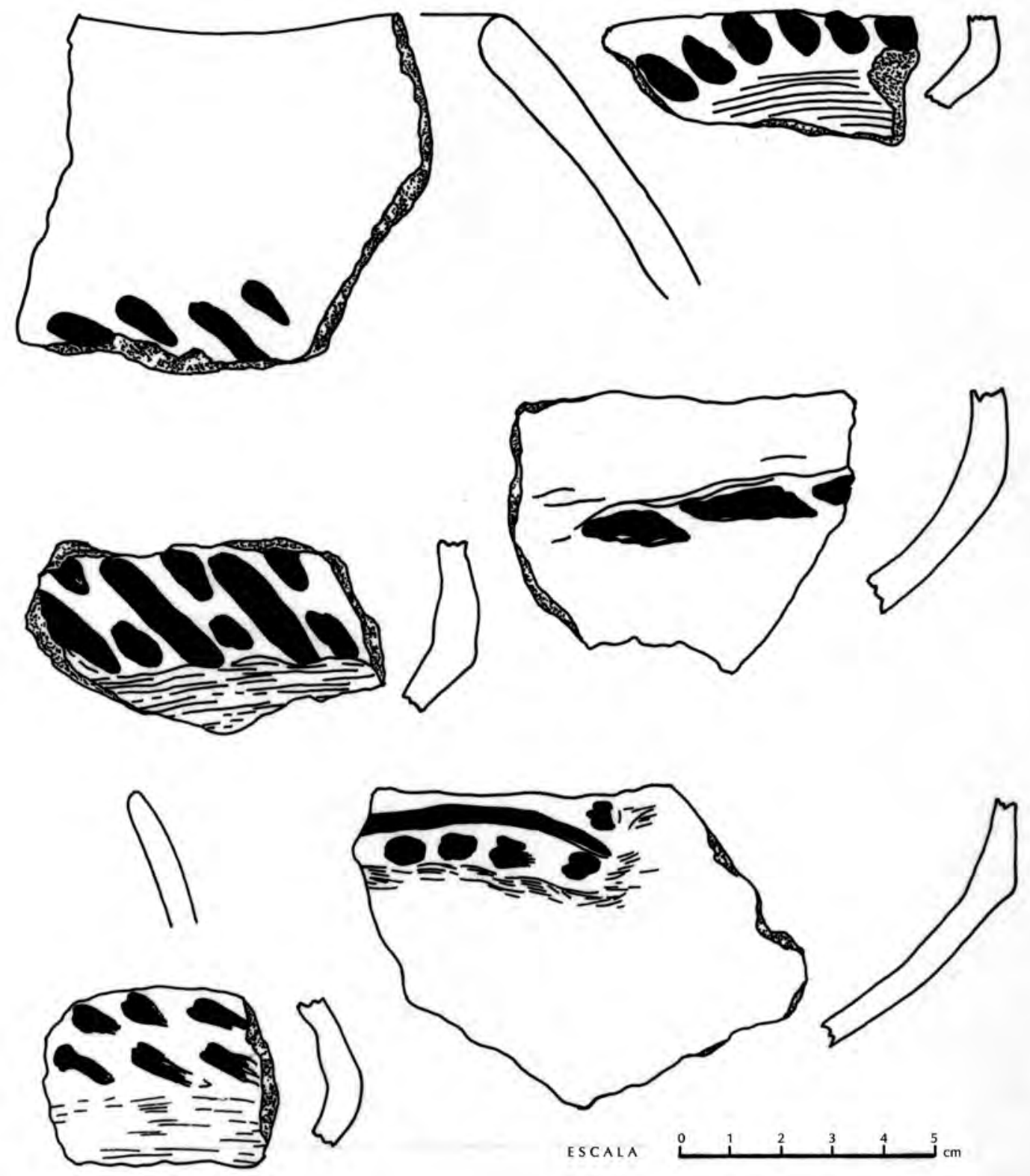

Fig. a, c-d, f: Tortugas, Casma, b, e, g: CL, Casma. 

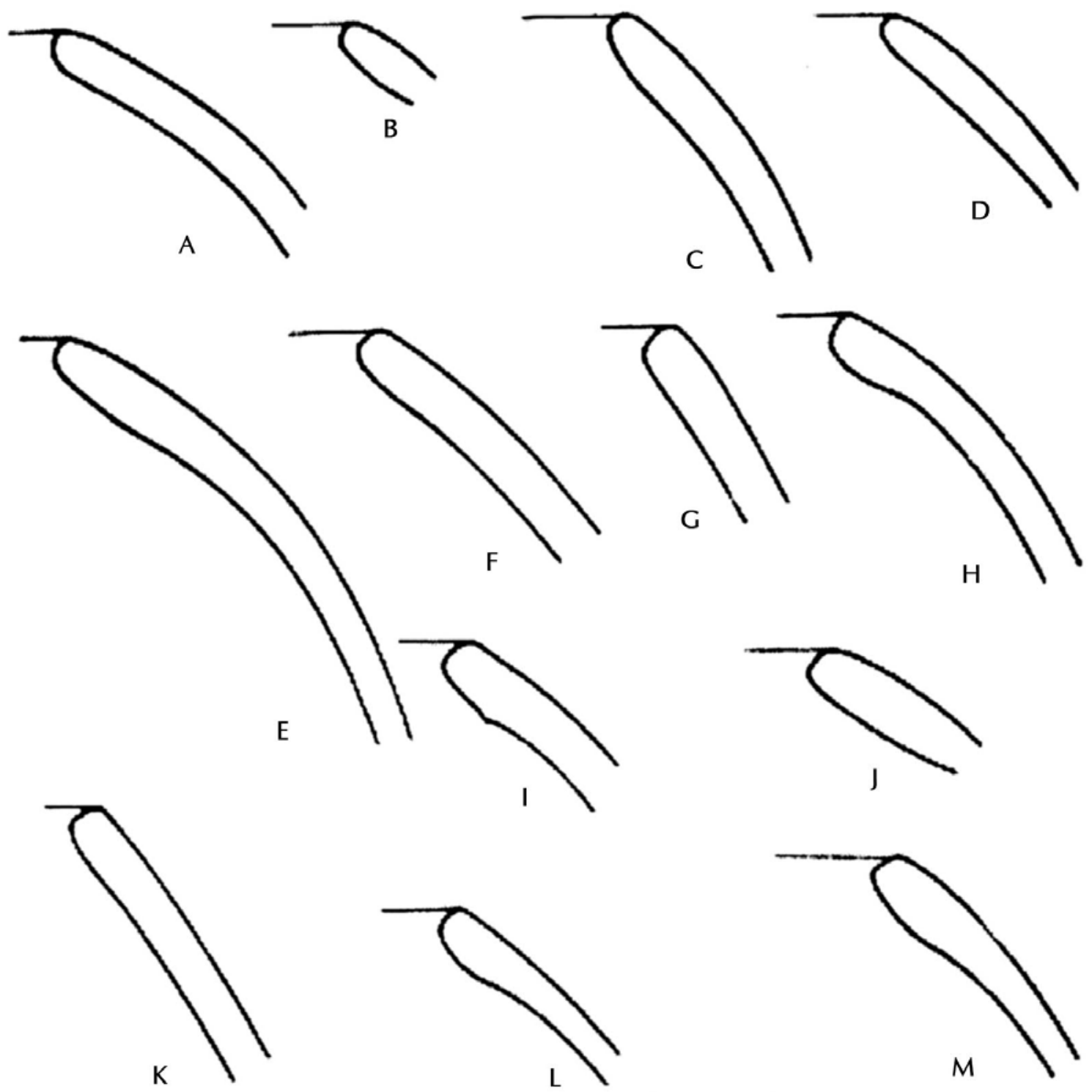

$\mathrm{E}$
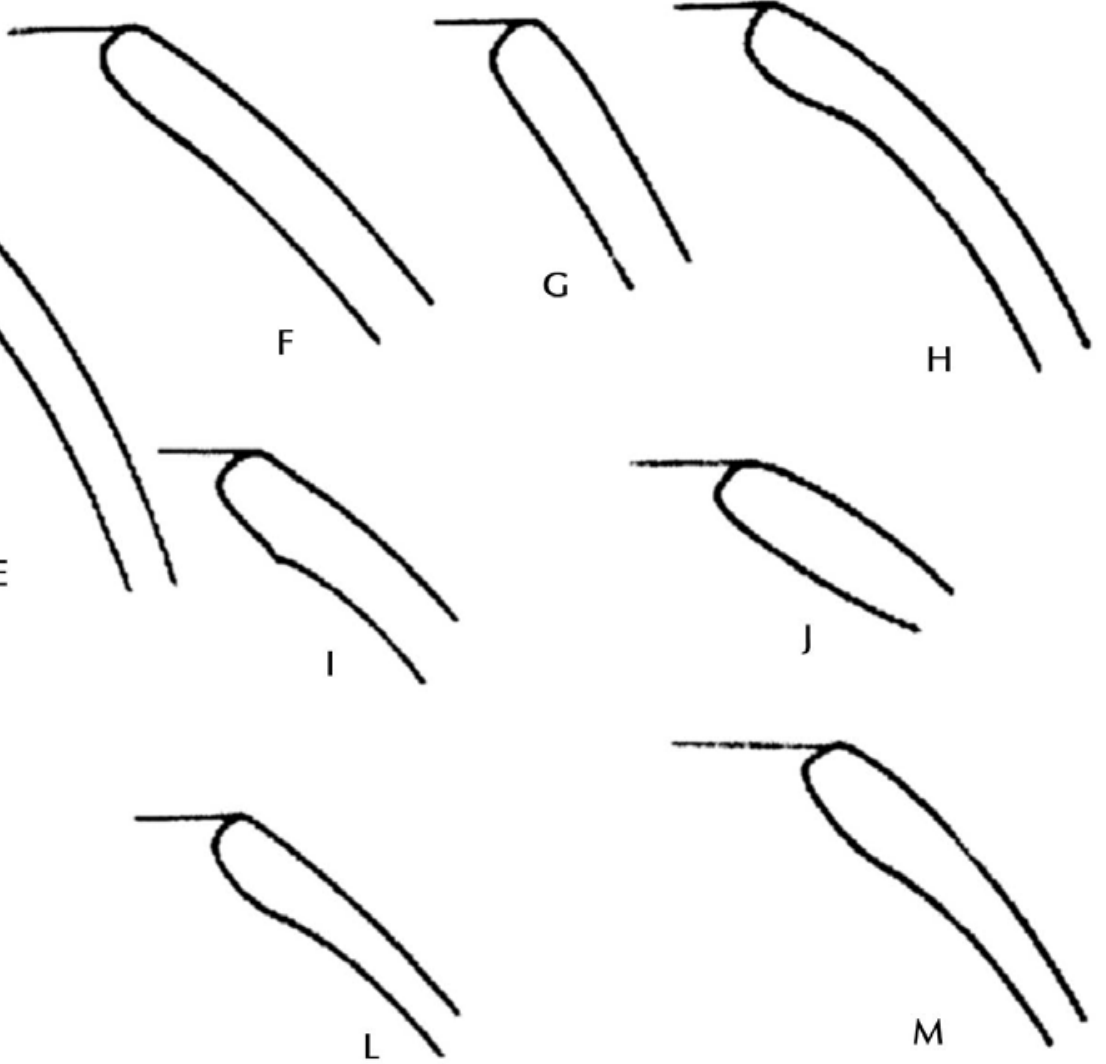

ESCALA

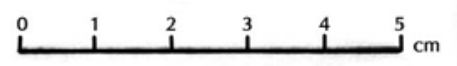

Fig. 2.- Bordes de la colección de Tortugas, Casma. 


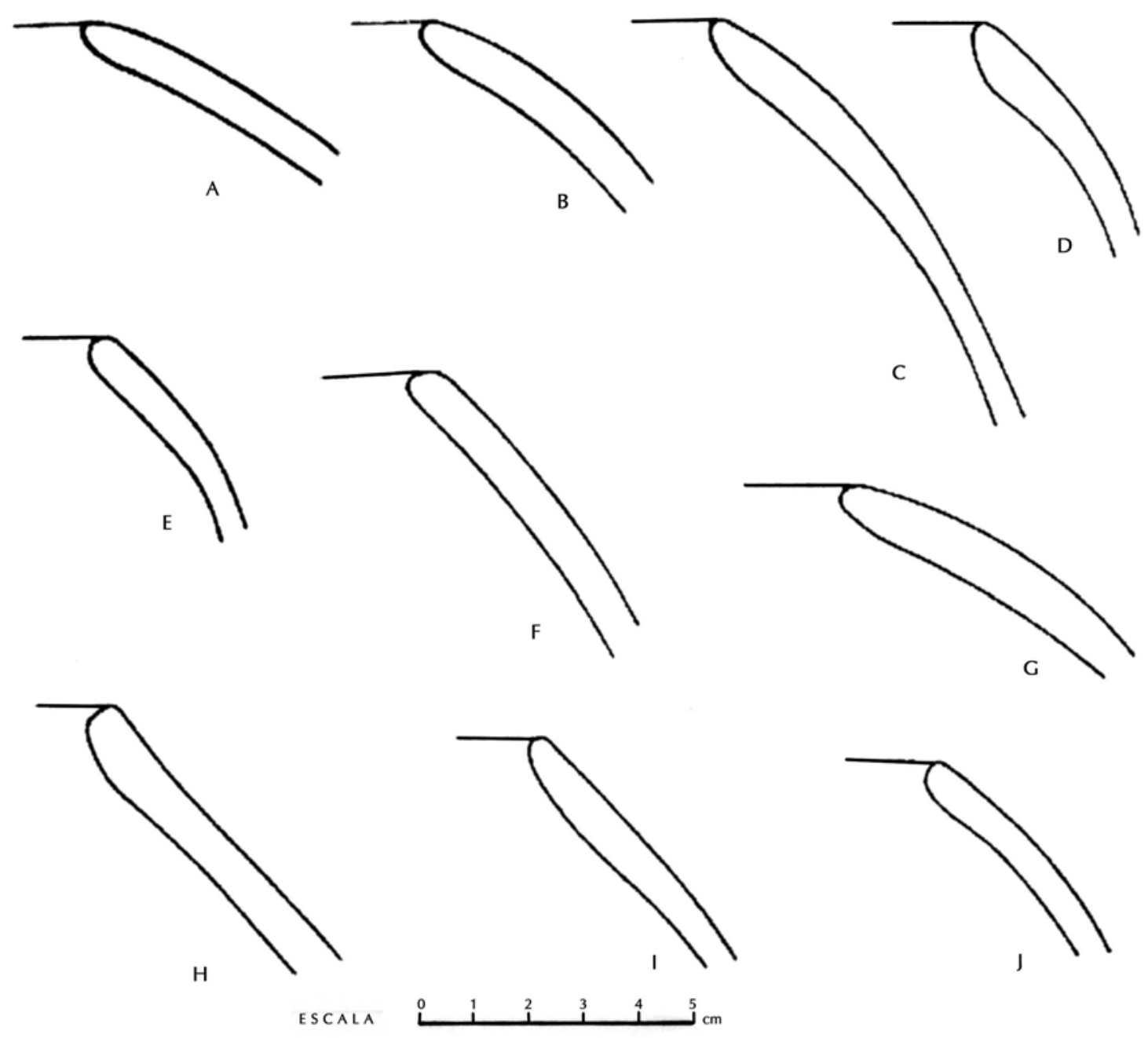

Fig. 3 Bordes de la colección de Tortugas, Casma. 


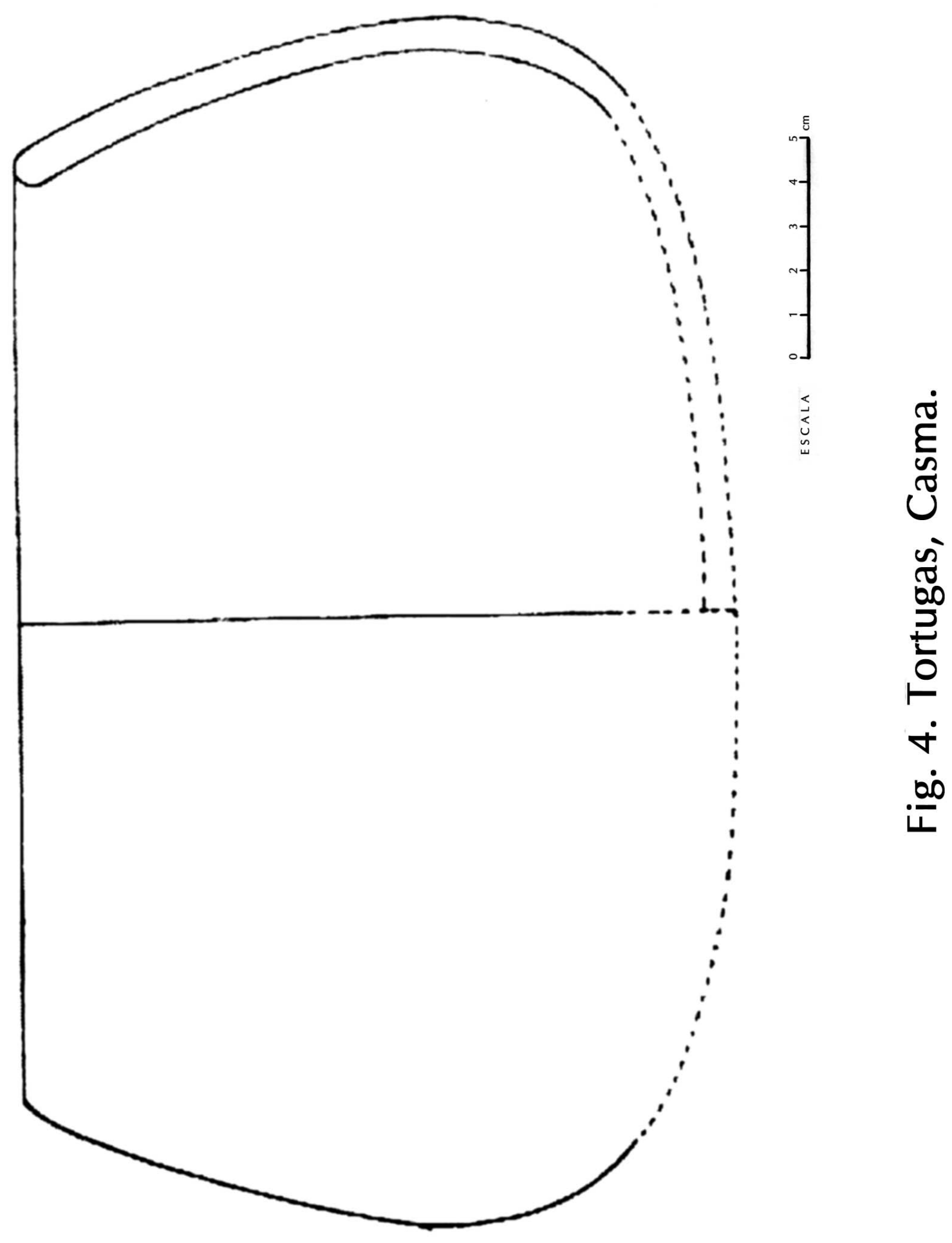



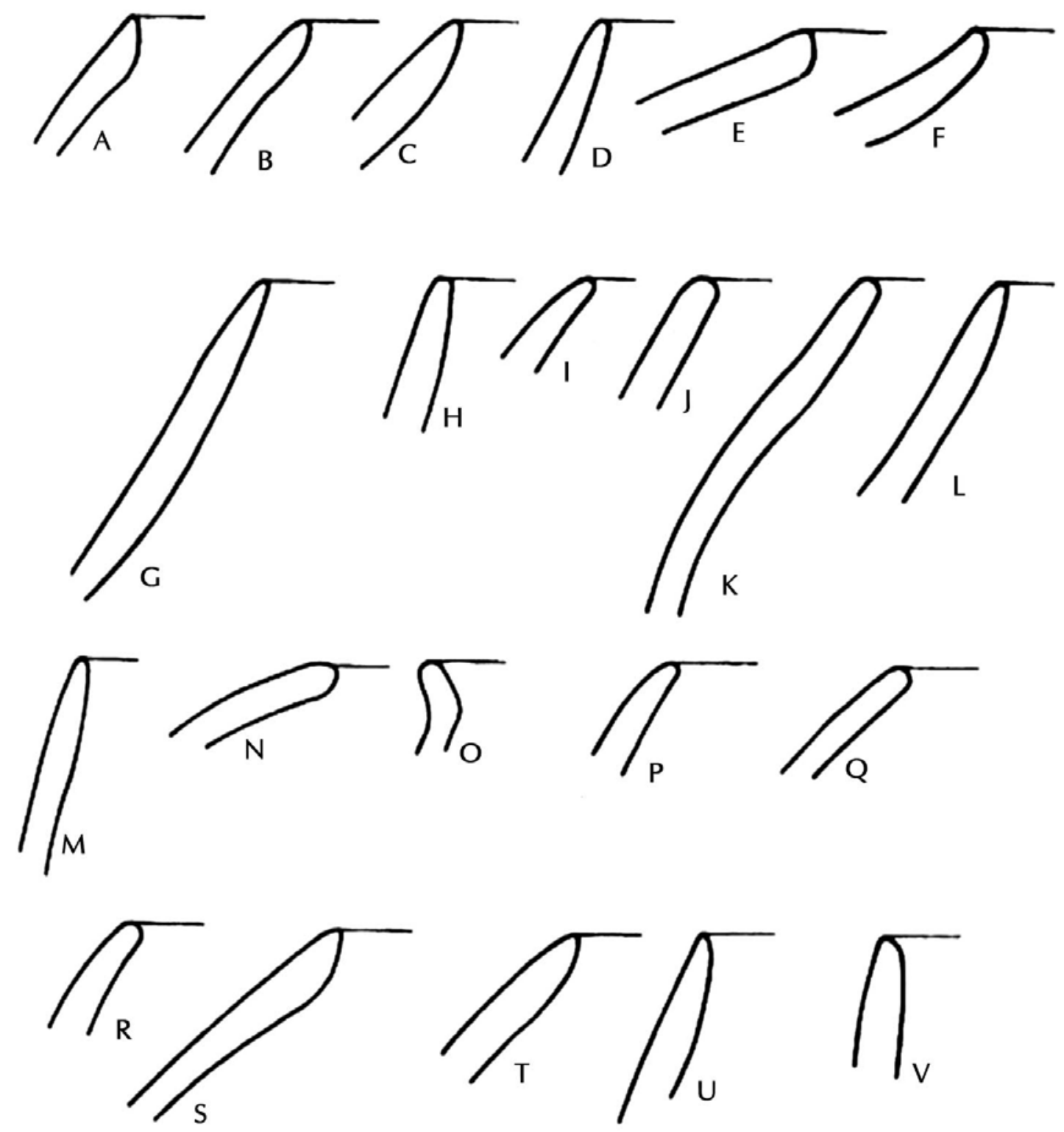

Fig. 5. Bordes de la colección Guañape, Virú. a-e: Guañape rojo sencillo, Smithsonian Institution, Cat. $403480(232,234,235,244,244,234,241,245,248,254,276,280)$. m-v: Guañape negro sencillo, Smithsonian Institution, Cat. 403481 (216, 234, 234, 245, 235, 241, 244, 245, 248, 280). 

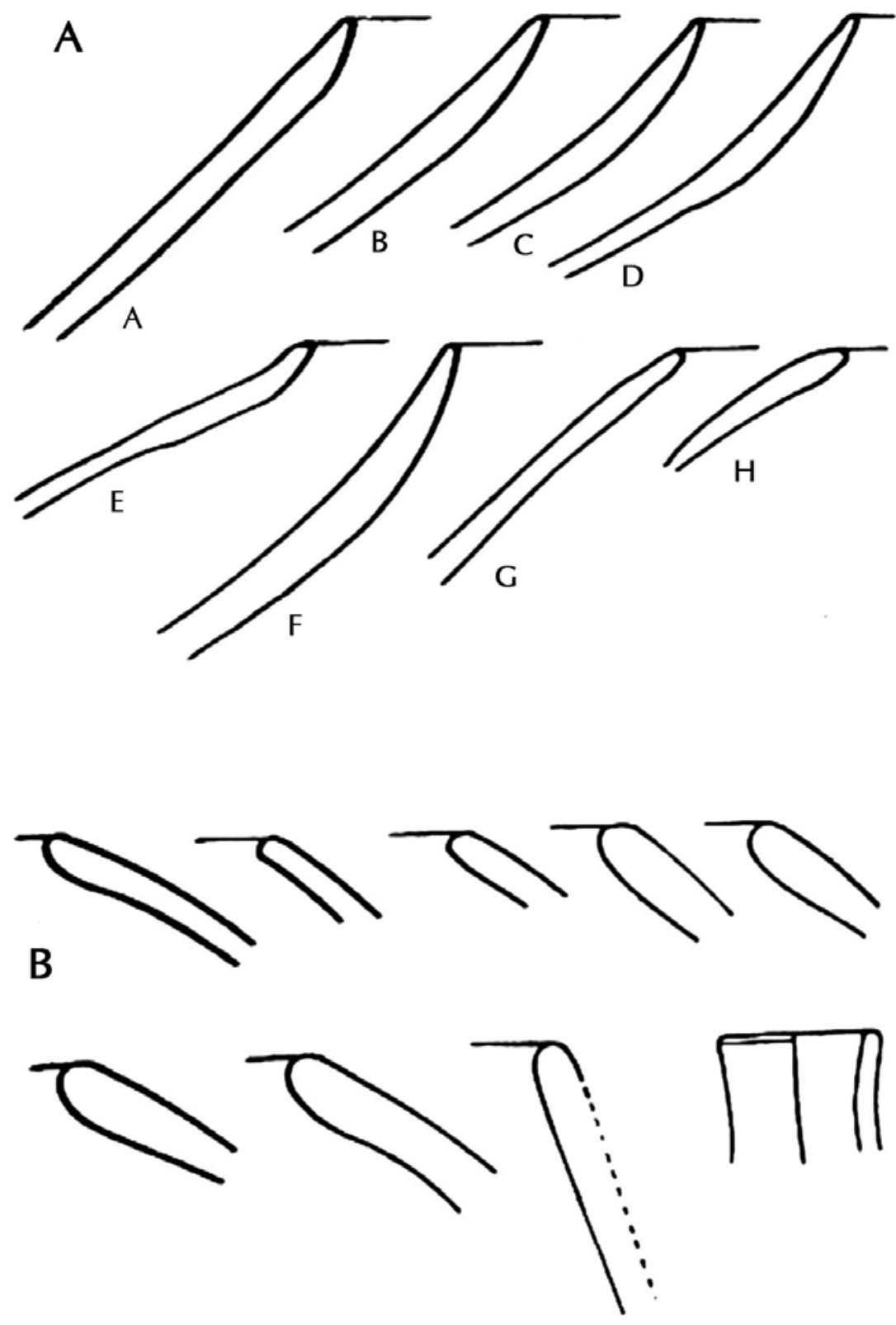

Fíg. 6, A: Bordes upre-Cupisniquen de Huaca Prieta. a-e: relleno de la Casa 2, Sondeo 4. f: Capa Z7 de la Trinchera del Sondeo 4. g-h: Capa Z6 de la Trinchera del Sondeo 4 (Tomado de los apuntes del Dr. Junius Bird). B: Bordes de la fase 1 de cerámica inicial de las Aldas. 